\title{
Brittle Strength of the VVER Pressure Vessel Steels under Operation Conditions
}

\author{
A. D. Erak¹, E. A. Kuleshova ${ }^{1,2}$, and S. A. Bubjakin ${ }^{1}$ \\ ${ }^{1}$ National Research Center "Kurchatov Institute", Akademika Kurchatova pl. 1, Moscow, Russia, \\ 123182 \\ ${ }^{2}$ National Research Nuclear University MEPhl (Moscow Engineering Physics Institute), \\ Kashirskoe shosse 31, Moscow, 115409, Russia
}

\section{Abstract}

Complex of mechanical tests and fractographic studies of various sample types were conducted for VVER pressure vessel steels. The brittle fracture sources (origins) were revealed: "non-metallic inclusions" and "structural boundaries". The computationalexperimental technique for evaluation of the local normal stress parameter that characterizes strength of the origin was performed. Values of the local normal stress

Corresponding Author:

E. A. Kuleshova

evgenia-orm@yandex.ru

Received: 21 December 2017

Accepted: 15 April 2018

Published: 6 May 2018

Publishing services provided by

Knowledge E

(c) A. D. Erak et al. This article is distributed under the terms of

the Creative Commons

Attribution License, which permits unrestricted use and redistribution provided that the original author and source are credited.

Selection and Peer-review under the responsibility of the MIE-2017 Conference Committee.

\section{G OPEN ACCESS} for the "structural boundary" origin type was demonstrated to be decreasing after thermal and radiation embrittlement due to decreasing in cohesive strength of grain boundaries by virtue of thermo- and radiation- stimulated diffusion of the impurities to grains boundaries.

Keywords: reactor pressure vessel, fractography, local normal stress, brittle fracture, origin

\section{Introduction}

Reactor pressure vessel during operation is influenced by high temperature and irradiation that bring about degradation of RPV material properties and at the end can result in the dangerous type of fracture: brittle fracture [1-4]. To evaluate brittle strength of the reactor pressure vessel steels the "local approach" [5] to steels brittle fracture is often used. The key issue in the "local approach" is statement of brittle fracture criterion in general using main components of stress and strain.

Fractographic studies of sample fracture surfaces permits to reveal the brittle fracture sources: origins. The use of computational-experimental investigation methods provides to determine local strength characteristics of the origins, e.g., local normal stress that promotes better understanding of material embrittlement mechanisms [6].

An objective of this work was to determine the local normal stress with use of cylindrical samples with the annular notch tested for uniaxial static tension and $\mathrm{SE}(\mathrm{B})$ samples with one-side notch and grown fatigue crack tested for fracture toughness. All 
samples were made of VVER pressure vessel steels in the initial and embrittled states. Determination of the origin type and its strength after influence of operational factors (temperature and irradiation) makes it possible to ascertain embrittling mechanisms for VVER RPV's steels.

\section{Materials and methods}

Base metal of the research reactor-prototype "Reactor $27^{\prime \prime}$ in the highly embrittled state after 30 years of operation at the temperature of $275^{\circ} \mathrm{C}$ was used as test material. Investigations of surveillance-specimens (SS) of the VVER-1000 reactor pressure vessel steels (RPV's): base metal (BM) and weld metal (WM) in the initial and irradiated (fluence $3.3 \div 4.8 * 10^{23} \mathrm{~m}^{-2}$, irradiation time of 16 years) states and after long thermal exposure during 23 years (200000 h) were also performed. The chemical composition of steels under study is given in Table 1.

TABLE 1: Chemical composition of materials under study.

\begin{tabular}{|c|c|c|c|c|c|c|c|c|c|}
\hline \multirow[t]{2}{*}{ Material } & \multicolumn{9}{|c|}{ Content of a chem. element, $\%$ wt } \\
\hline & $\mathrm{C}$ & $\mathrm{Si}$ & $\mathrm{Mn}$ & $\mathrm{Cr}$ & $\mathrm{Ni}$ & Mo & $S$ & $P$ & $\mathrm{Cu}$ \\
\hline Base metal «Reactor $27 »$ & 0.25 & 0.31 & 0.47 & 3.30 & 1.07 & 0.37 & 0.040 & 0.018 & 0.10 \\
\hline Base metal 15 Ch2NMFA-A & $\begin{array}{l}0.13- \\
0.16\end{array}$ & $\begin{array}{l}0.17^{-} \\
0.37\end{array}$ & $\begin{array}{l}0.3^{-} \\
0.6\end{array}$ & $\begin{array}{c}1.8- \\
2.3\end{array}$ & $\begin{array}{c}1.0^{-} \\
1.5\end{array}$ & $\begin{array}{c}0.5^{-} \\
0.7\end{array}$ & $\begin{array}{l}0.01^{-} \\
0.02\end{array}$ & $\begin{array}{l}0.01^{-} \\
0.02\end{array}$ & $\begin{array}{l}0.08- \\
0.30\end{array}$ \\
\hline $\begin{array}{c}\text { Weld metal } \\
\text { Sv-10ChGNMA-A }\end{array}$ & $\begin{array}{c}0.06- \\
0.12\end{array}$ & $\begin{array}{l}0.15^{-} \\
0.45\end{array}$ & $\begin{array}{l}0.65^{-} \\
1.10\end{array}$ & $\begin{array}{l}1.2^{-} \\
2.0\end{array}$ & $\begin{array}{l}1.2- \\
1.8\end{array}$ & $\begin{array}{c}0.4^{-} \\
0.7\end{array}$ & $\leq 0.02$ & $\leq 0.025$ & $\leq 0.15$ \\
\hline
\end{tabular}

To determine the local normal stress the uniaxial static tension tests of cylindrical specimens with annular notch and the fracture toughness tests of $S E(B)$-type specimens were made. Selection of the annular notched specimen geometry was contingent on occurring of the maximum normal stresses in center of specimen cross-section providing correct normal stress determination. The SE(B)-type samples has the sharp stress concentrator (grown fatigue crack) that provides maximum of stress in the area close to the crack tip.

\subsection{States under study}

To evaluate influence level of the thermal embrittlement on the local normal stress value it is necessary to compare data for the initial and embrittled states. However, data for the initial material state of the research "Reactor 27 " is absent. Consider that 
"Reactor 27 " steel was affected by long thermal exposure (at a reactor operation temperature) the base factor for material embrittlement was thermal induced Phosphorus segregation [7]. To receipt the "initial-like" state it was proposed to use the high temperature annealing with the regime $680^{\circ} \mathrm{C} / 50 \mathrm{~h}$ including rapid cooling in water. That temperature interval is higher than the one where the maximum level of reversible temper brittleness effect occurs. This regime is similar to the regime of final thermal processing of RPV steels of this class. To prevent increasing of phosphorus segregation at grain boundaries during passing through the interval of reversible temper brittleness cooling in water of the material was used.

To confirm efficiency of recover annealing using pre-determined regime Augier electron studies for assessment of phosphorus segregation degree at grain boundaries of the material in various states: before and after annealing has been made.

Diagram of phosphorus distribution at grain boundaries is shown in Figure 1.

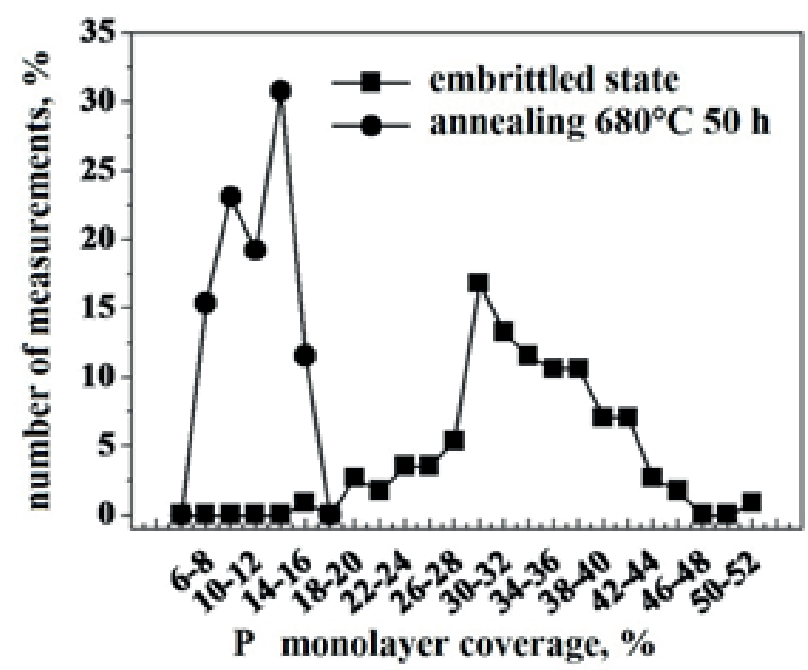

Figure 1: Phosphorus distribution at grain boundaries in the embrittled and annealed states.

Figure 1 shows that the annealing with pre-determined regime $680^{\circ} \mathrm{C} / 50$ has decreased the phosphorus segregation level in the annealed steel to values peculiar to RPV steels in the initial state.

Brittle intergranular fracture portion measured in fracture surfaces of the tested annealed samples compose $\sim 5 \%$ and for the embrittled samples is $\sim 80 \%$. Considering that brittle intergranular fracture portion correlates to grain boundary segregation degree the increase in strength of grain boundaries confirms decrease of the grain boundary segregation level in annealed samples [7].

To evaluate influence of irradiation level on the local normal stress values the surveillance-specimens (SS) of VVER-100o RPV base metal (BM) and weld metal (WM) were studied in the initial and irradiated states and also after long thermal exposures. 


\subsection{Fractographic studies technique}

To observe the brittle fracture sources (origins) the fractographic investigations of cylindrical samples with annular notch and $\mathrm{SE}(\mathrm{B})$ samples with one-side notch and grown fatigue crack were conducted.

Fractographic investigation technique [8] involves determination of location and type of an origin and also measurement of the cleavage initiation distance (CID). Cleavage initiation distance is the distance from origin to the fatigue crack tip.

Measurement of CID values for various types of samples was made in various ways. For cylindrical samples with annular notch the center of the sample was defined in fracture surface (see Figure 2a). Next, analyzing at higher magnifications the "river lines" of transgranular fracture location of the brittle fracture origin and its type were determined. Afterwards, the distance CID from center of the sample to the identified origin was measured (see Figure $2 b$ ).

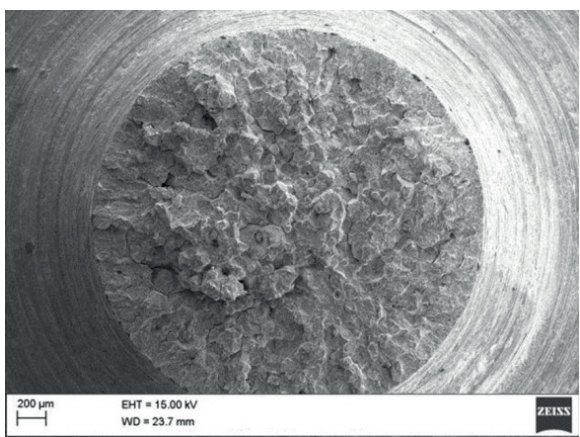

(a) panoramic view of fracture surface of the cylindrical sample

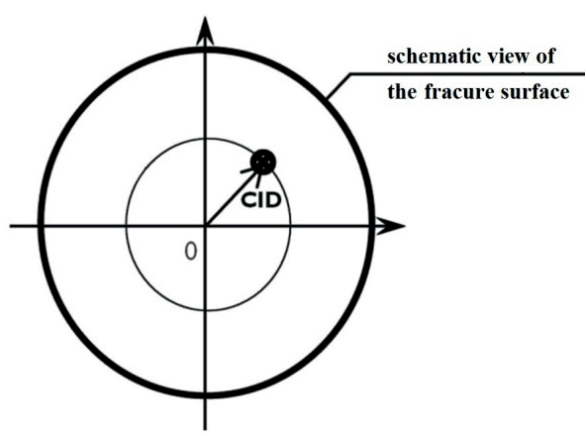

(b) CID measurement scheme

Figure 2: Investigation technique of fractographic studies of the cylindrical samples with annular notch.

Investigation of fracture surfaces of the $S E(B)$-type samples after fracture toughness tests were conducted using the following technique. On the panoramic view of the fracture surface (see Figure $3 a$ ) observing the disperse relief of fracture the brittle fracture initiation region was determined. Next, at higher magnifications the proposed location of the brittle fracture origins in the initiation zone was defined by the "river lines" of transgranular fracture; and the distance CID from the origin to the grown fatigue crack tip was measured (see Figure $3 b$ ).

Base on the fractographic analysis results of all studied samples two types of origins: "structural boundary" (transgranular or intergranular) (see Figure 4 a,b) and "nonmetallic inclusion" (see Figure 4c) were revealed. 


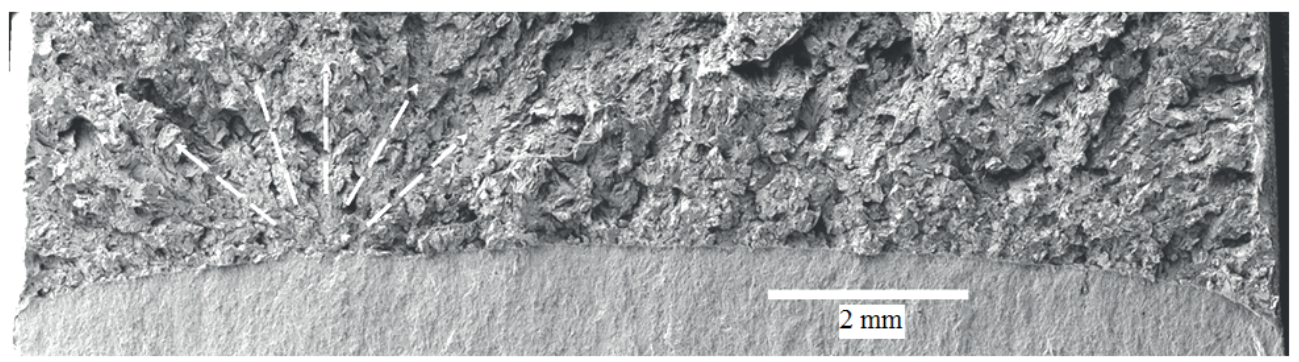

(a) Panoramic view of SE(b) sample fracture surface

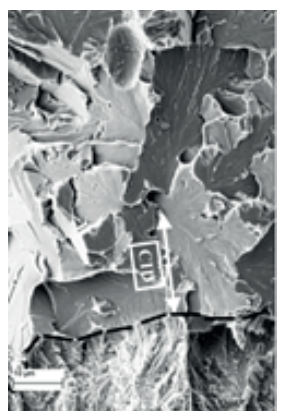

(b) origin location zone

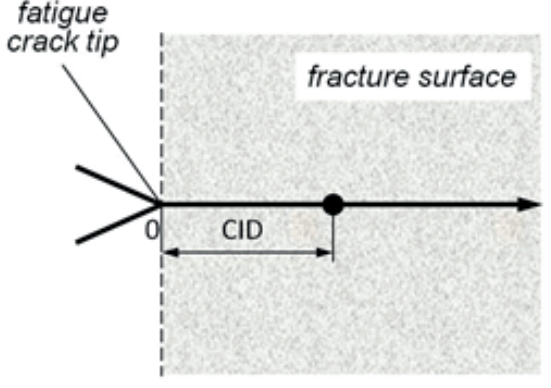

(c) CID measurement scheme

Figure 3: Fractographic investigation technique for $S E(B)$ samples with one-side notch and grown fatigue crack.

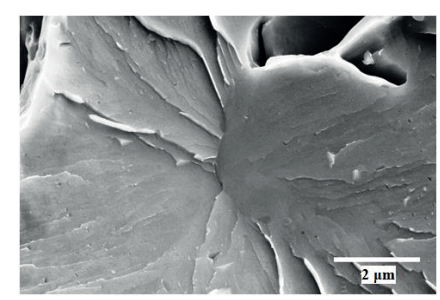

(a) transgranular grain boundary

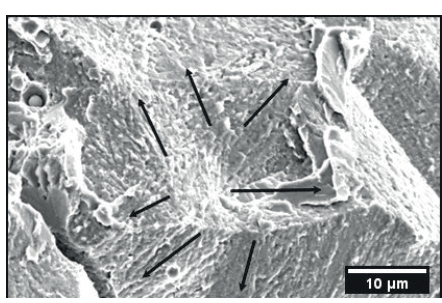

(b) intergranular grain boundary

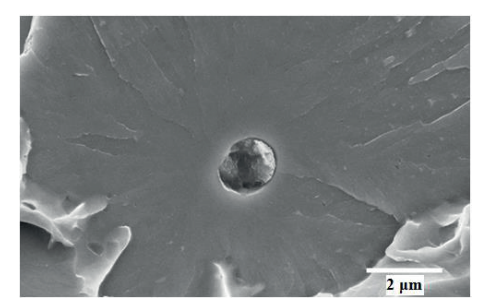

(c) non-metallic inclusion

Figure 4: Origin types.

\subsection{Computational-experimental technique of stress-strain state determination}

Finite element models $[6,9]$ composed of large amount of quadric 3-D finite elements and nodes were developed to define the stress-strain state (SSS) of cylindrical samples with annular notch tested for uniaxial static tension and $\mathrm{SE}(\mathrm{B})$ samples with one-side notch and grown fatigue crack tested for fracture toughness. Fine grid was used tor more accurate determination of SSS parameters in the vicinity of annular notch and the fatigue crack tip (for SE(B)-type samples). Individual geometry of the notch front was considered for each sample. Every sample was loaded with several loading steps until critical point where fast fracture occurs. 
The task of SSS calculation was solved in the elastic-plastic set up within the framework of plastic flow theory [10] inclusive of large deformations and changes in physical dimensions of sample at each loading step.

\section{Discussion of the investigated results}

\subsection{Calculation of stress-strain state}

Figure 5 shows the typical distribution of normal stress components $\left(\mathrm{S}_{x}, \mathrm{~S}_{y}, \mathrm{~S}_{z}\right)$ in crosssection of the annular notched sample (Fig. 5 a,b) and one-side notched sample (Fig. $5 c, d)$.

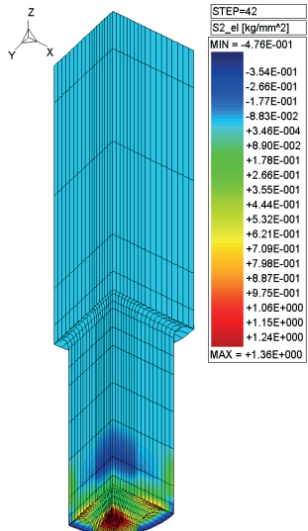

(a)

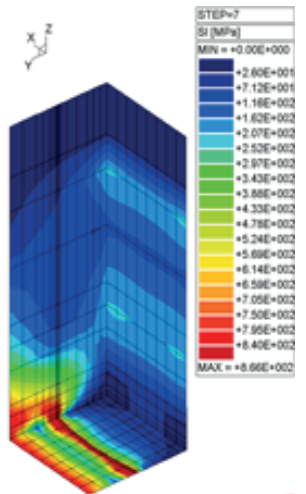

(c)

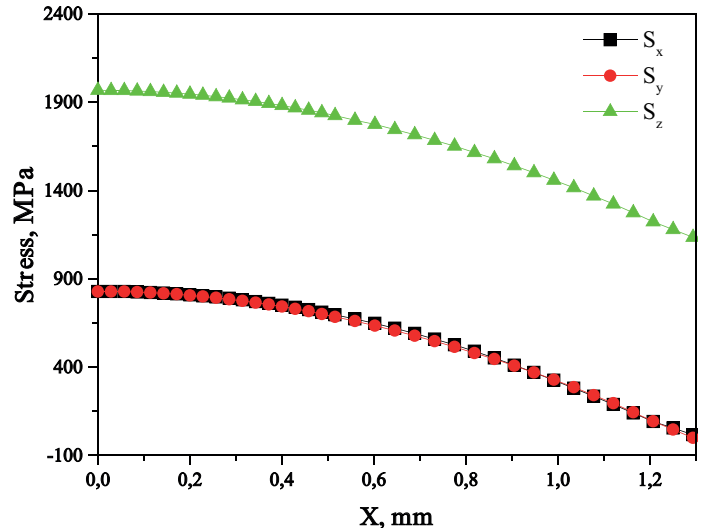

(b)

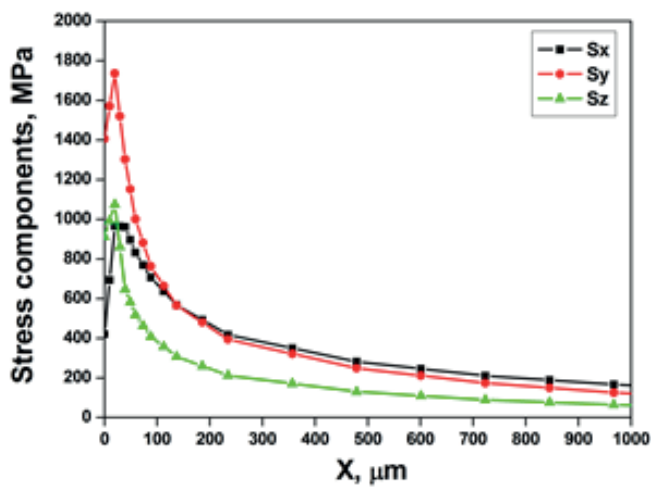

(d)

Figure 5: Example of SSS calculation for cylindrical sample $(a, b)$ and $\operatorname{SE}(B)$-type sample $(c, d)$.

As can be seen from Figure 5 the maximum and determine value for brittle crack initiation of the three normal stress components has $S_{y}$ component (normal opening direction). 


\subsection{Determination of the local normal stress}

To determine the local normal stress values for observed origins in each sample the following procedure was used:

- CID determination with data selection for each origin type (see Figures $2 b$ and $3 b)$;

- Using $S_{y}$ stress distribution for particular sample the local normal stress values were calculated in accordance with coordinate of the observed origin.

In Table 2 an average values of determined local normal stresses $\left(S_{n}\right)$ for observed origins revealed in every group of samples with partition by sample type (cylindrical and SE(B)-type) and also by condition (initial, thermo-embrittled, irradiated) are presented.

TABLE 2: Determination results of the local normal stress $\left(S_{n}\right)$ for cylindrical and SE(B) samples.

\begin{tabular}{|c|c|c|c|}
\hline Origin type & Material & Condition & $S_{n}, \mathrm{MPa}$ \\
\hline \multirow[t]{8}{*}{ "NI"** } & "Reactor 27 " BM & Annealed ("initial") & 2100 \\
\hline & & Thermo-embrittled & - \\
\hline & VVER-1000 BM & Initial & 1900 \\
\hline & & Thermo-embrittled & 2000 \\
\hline & & Irradiated & 2100 \\
\hline & VVER-1000 WM & Initial & 2000 \\
\hline & & Thermo-embrittled & 2100 \\
\hline & & Irradiated & 2200 \\
\hline \multirow[t]{8}{*}{ "SB"** } & "Reactor 27 " BM & Annealed ("initial") & 2150 \\
\hline & & Thermo-embrittled & 1900 \\
\hline & VVER-1000 BM & Initial & 2600 \\
\hline & & Thermo-embrittled & 2200 \\
\hline & & Irradiated & 2200 \\
\hline & VVER-1000 WM & Initial & 2700 \\
\hline & & Thermo-embrittled & 1900 \\
\hline & & Irradiated & 2000 \\
\hline $\mathrm{NI}$ is a "non & allic inclusion"; & & \\
\hline
\end{tabular}


Table 2 shows that for the "Reactor 27 " BM tested in the embrittled state the type of brittle fracture origin is "structural boundary" of the high angle boundary type only. After annealing fracture behavior has been changed: types of brittle fracture origin were "structural boundaries" of sub-grain type and "non-metallic inclusions". Presence of non-metallic inclusion as an origin type in annealed material indicates that the strength of the grain boundaries has increased relatively to the embrittled state; and the weakest link in the material was non-metallic inclusion/matrix boundary. This is also confirmed by the fact that for the annealed state the values of local normal stress for "structural boundary" origin type are higher than for the embrittled state. Consequently, the cohesive strength of grain boundaries in the embrittled state depends on influence of thermal induced phosphorus segregation [11-12].

To compare the investigation results of steels tested in various states (also at various temperatures) and to calculate an analytical dependences between the fracture toughness parameters and the structural parameters of SE(B) samples CTOD (crack tip open displacement) parameter was chosen as a fracture toughness parameter. The critical value of CTOD parameter was calculated using equation (1) [13]:

$$
C T O D=\frac{K_{J c}^{2}}{2 * E * R p_{0.2}} *\left(1-v^{2}\right),
$$

where $K_{J c}$ is stress intensity factor;

$E$ is Young's modulus;

$R p_{0.2}$ is yield strength;

$v$ is Poisson coefficient.

B.c.c. steels including VVER RPV steels are characterized by the temperature dependence of yield strength and Young's modulus. The use of CTOD parameter as a fracture toughness parameter permits comparison of fracture toughness results for various test temperatures.

Figure 6 shows the diagram of local normal stress determination for various origin types observed in $\mathrm{SE}(\mathrm{B})$ samples.

As it follows from Figure 6 the smaller slope angle of the CTOD(CID) dependence corresponds to the lower values of local normal stress because $S_{y}$ stress component is decreasing with the increase of distance from the crack tip. This implies that for equal fracture toughness values the origin strength is decreasing.

Data comparison for the BM and WM with "non-metallic inclusion" ("NI") and "structural boundary" ("SB") origin types is presented in Figure 7.

To prove equality hypothesis of $\operatorname{CTOD(CID)}$ dependence coefficients for samples tested in the initial state and after thermal exposure the Chow test [14] was used. 


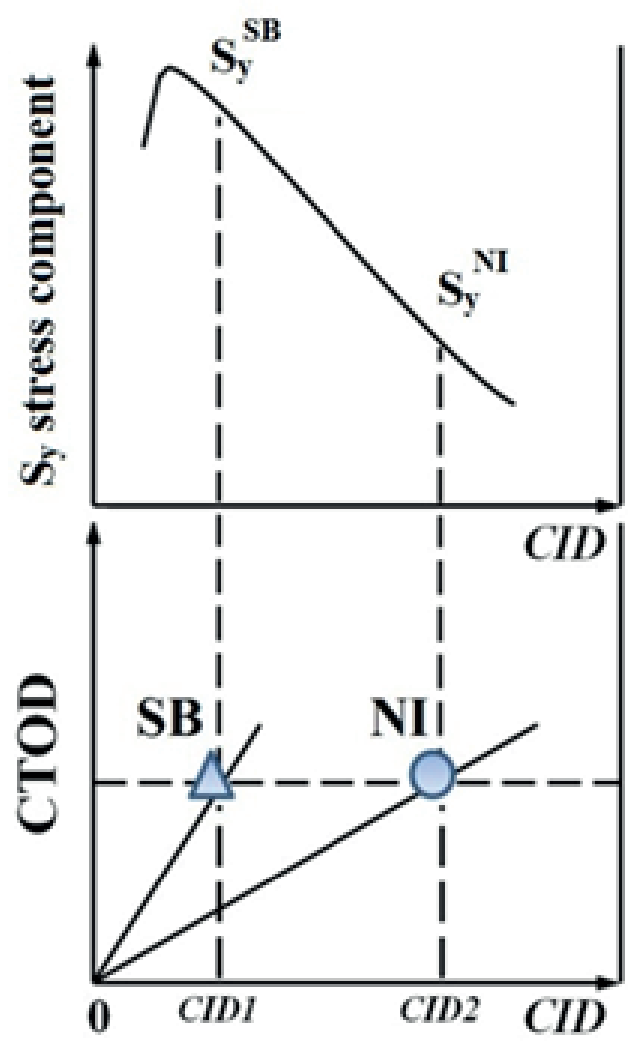

Figure 6: Diagram of local normal stress determination for various origin types and an example of CTOD(CID) dependences.

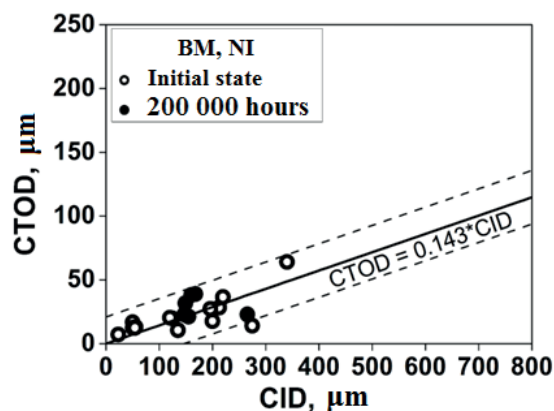

(a)

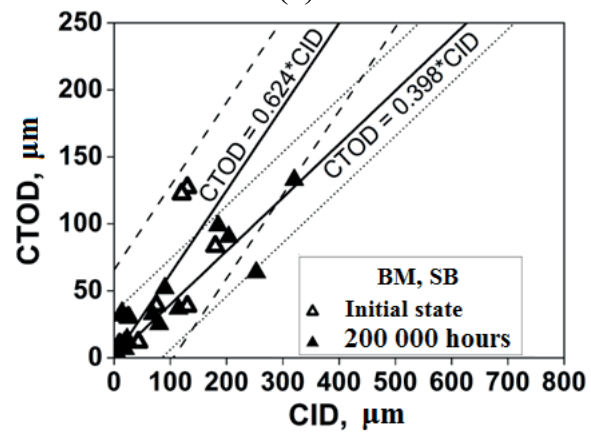

(c)

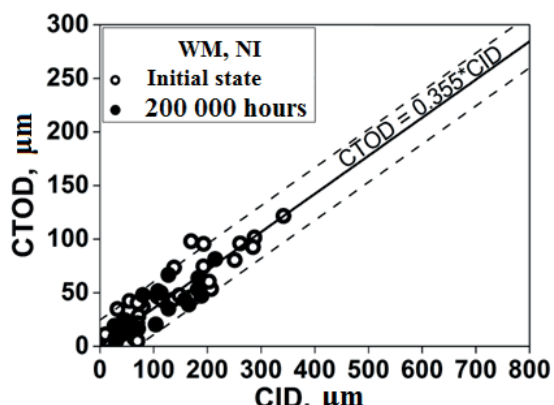

(b)

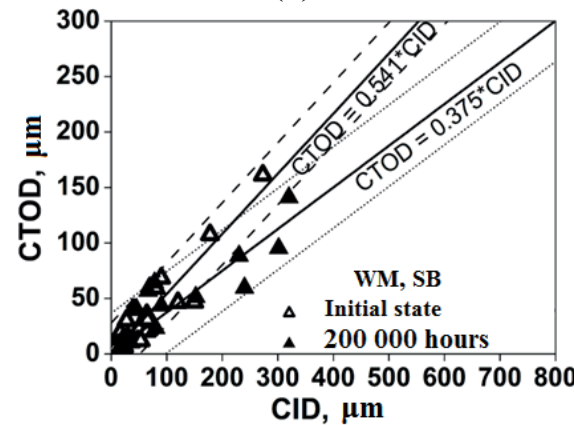

(d)

Figure 7: Correlation between the crack tip open displacement and CID parameter. BM $(a, c)$ and WM (b,d) data after thermal exposure during $200000 \mathrm{~h}$. 
Figure $8(a, b)$ shows $\mathrm{CTOD}(\mathrm{CID})$ dependences for "NI" origin type observed in BM and WM and data for "structural boundary" origin typ (see Figure $8(c, d)$ ). Data for the initial and the irradiated states was processed using Chow test.

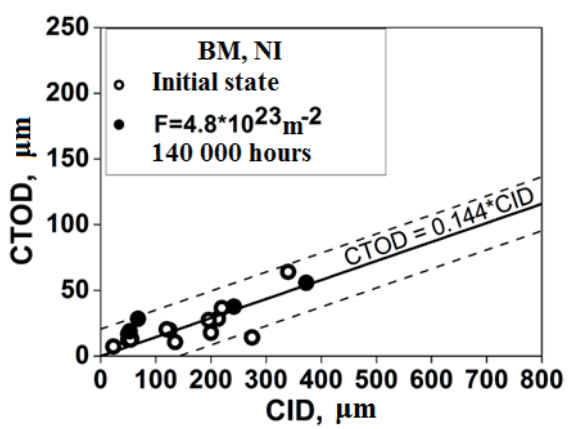

(a)

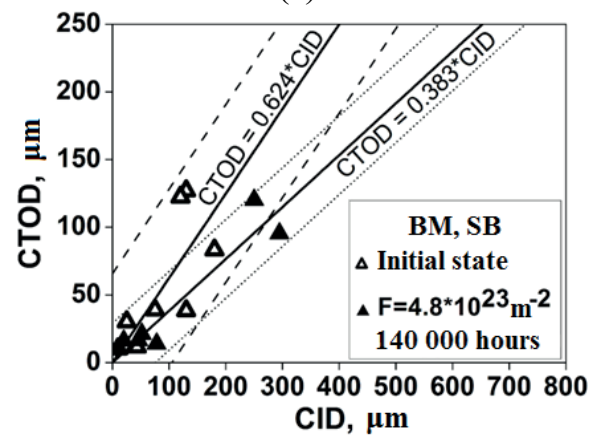

(c)

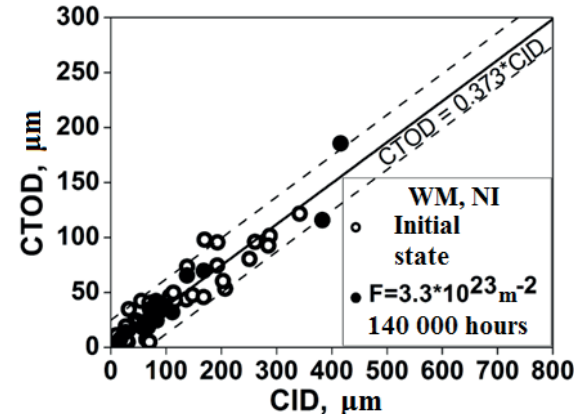

(b)

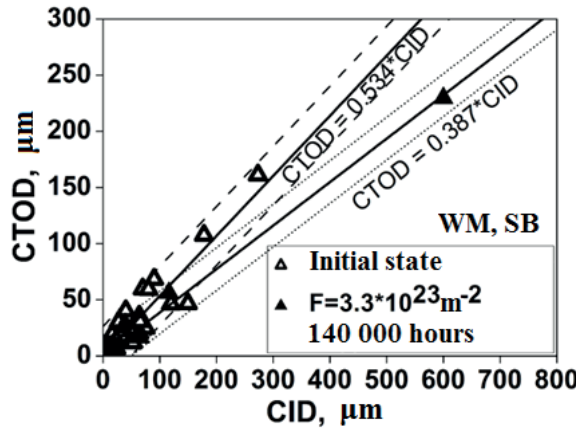

(d)

Figure 8: Correlation between the crack tip open displacement and CID parameter. BM $(a, c)$ and WM (b,d) data after irradiation during $140000 \mathrm{~h}$.

An analysis of Figures 8 and 9 shows that for "NI" origin type the slope angle of CTOD(CID) dependence along with local normal stress practically does not change after long thermal exposure during $200000 \mathrm{~h}$ and also after irradiation (fluence $\sim 4^{*} 10^{23} \mathrm{~m}^{-2}$ ) compare to the initial state as for BM so for WM (see Table 2).

For "SB" origin type for thermal exposure during $200000 \mathrm{~h}$ slope angle of CTOD(CID) dependence is decreasing. This points to the fact that the local normal stress for "SB" origin type is decreasing compare to the initial state as for BM so for WM. This proposition is confirmed by the received data (see Table 2 ).

An analysis of BM and WM data for "SB" origin type shows that slope angle of CTOD(CID) dependence for the irradiated state is lower than for the initial state. That indicates the decrease in the local normal stress value for structural boundaries in the irradiated state.

As follows from Table 2 for the BM and WM with "SB" origin type the local normal stress has decreased after irradiation with simultaneous influence of thermal exposure during $140000 \mathrm{~h}$ for the BM and WM with "SB" origin type compare to the initial state. The values of local normal stress for the irradiated state with a shorter exposure time 
(140000 h) corresponds to a values that are typical for the thermal exposures during 200000 h. Consequently, reduction in the cohesive strength of the grain boundaries was a consequence of both thermal and radiation-induced diffusion of impurities along the grain boundaries [7].

Thus, it has been shown that influence of the operational temperatures as well as fast neutron irradiation leads to the preferential type of brittle fracture origin: "structural boundary" both in case of the uniaxial static tension test and fracture toughness test. This fact linked with the increase of segregation processes rate (primarily of $P$ ) in the RPV steels with b.c.c.-lattice type and as a consequence leads to a decrease in the cohesive strength of grain boundaries and in the local normal stress values for such boundaries.

\section{Conclusions}

1. Investigations of the cylindrical samples with an annular notch for base metal of the reactor-prototype "Reacror 27 " in the embrittled state and after laboratory annealing with the regime $680^{\circ} \mathrm{C} / 50 \mathrm{~h}$ leading the material to the initial state were conducted. SE(B) surveillance-specimens of VVER-1000 RPV base metal and the weld metal in the initial and irradiated states were also investigated.

2. Stress-strain states of samples tested for uniaxial static tension and fracture toughness were determined using the computational-experimental technique with use of finite-element model.

3. By means of fractographic analysis the brittle fracture origin were revealed in tested samples. For all states under study two origin types were observed: "nonmetallic inclusion" and "structural boundary".

4. Local normal stress values for different origin types characterizing its strength were defined for samples tested in various states.

5. It was shown that in highly embrittled samples the main origin type is "grain boundary". After annealing $680^{\circ} \mathrm{C} 50 \mathrm{~h}$ (returning the grain-boundary phosphorus concentration to the initial state level) different origin types were observed. This is due to increase in the cohesive strength of grain boundaries in consequence of dissolution of grain boundary segregation of phosphorus. In this case, the local normal stress appear to be lower for the samples tested in the embrittled state (on average, $1880 \mathrm{MPa}$ ) than after annealing $680^{\circ} \mathrm{C} 50 \mathrm{~h}$ (on average, $2110 \mathrm{MPa}$ ), which indicates a decrease in the local normal stress in the embrittled samples due to the presence of grain boundary segregation of phosphorus. 
6. In the irradiated samples, the local normal stress for the "structural boundary" origin type both for BM and WM is lower after neutron irradiation compare to the initial state and after influence of operational temperature only due to additional reduction in the cohesive strength of the grain boundaries in consequence of radiation-induced diffusion that leads to accelerated formation of grain boundary segregations of phosphorus.

\section{Acknowledgement}

Authors express their gratitude to Dr. Aleksandr S. Kiselev and to Dr. Aleksei S. Kiselev for their assistance in calculations of stress-strain state of samples.

\section{References}

[1] B.A. Gurovich, E.A. Kuleshova, Y.A. Nikolaev, Y.I. Shtrombakh. Assessment of relative contributions from different mechanisms to radiation embrittlement of reactor pressure vessel steels. Journal of Nuclear Materials, 1997, v. 246, N 2-3, pp 91-120.

[2] Ya.I. Shtrombakh, B.A. Gurovich, E.A. Kuleshova, D.A. Maltsev, S.V. Fedotova, A.A. Chernobaeva. Thermal ageing mechanisms of VVER-1000 reactor pressure vessel steels. Journal of Nuclear Materials, 2014, v. 452, N 1-3, PP 348-358.

[3] B. Gurovich, D. Maltsev, O. Zabusov, K. Prikhodko, A. Frolov, S. Fedotova, D. Erak, D. Zhurko, M. Saltykov. The effect of radiation-induced structural changes under accelerated irradiation on the behavior of water-cooled reactor pressure vessel steels. Key Engineering Materials, 2014, v. 592-593, pp 573-576.

[4] 0.0. Zabusov, B.A. Gurovich, M.A. Saltykov, S.V. Fedotova, A.P. Dementjev. Intergranular embrittlement of nuclear reactor pressure vessel steels. Key Engineering Materials, 2014, v. 592-593, pp 577-581.

[5] B.Z. Margolin, V.A. Shvetsova, G.P. Karzov. Brittle fracture of nuclear pressure vessel steels. Part I. Local criterion for cleavage fracture. Int. J. Pres. Ves. \& Piping, 1997, v. 72, PP 73-87.

[6] E.A. Kuleshova, A.D. Erak, A.S. Kiselev, S.A. Bubyakin, A.P. Bandura. Influence of operation factors on brittle fracture initiation and critical local normal stress in SE(B) type specimens of VVER reactor pressure vessel steels, Journal of Nuclear Materials, Vol. 467, 2015, pp 927-936.

[7] E.A. Kuleshova, B.A. Gurovich, Z.V. Lavrukhina, M.A. Saltykov, S.V. Fedotova, A.N. Khodan. Assessment of segregation kinetics in water-moderated reactors pressure 
vessel steels under long-term operation. Journal of Nuclear Materials, 2016, v. 477, PP 110-122.

[8] E.A. Kuleshova, A.D. Erak, M.A. Artamonov. Origins of brittle microcracks in crack resistance tests of steels of VVER-1000 vessel in various states, Inorganic Materials: Applied Research, Vol. 5, № 6(76), 2014, pp 626-634.

[9] O. Zenkevich. Finite element model in engineering. M.: Mir, 1975, P 541, in Russian.

[10] N.N. Malinin. Малинин H.H. Applicable theory of plasticity and creep. M.: Mashinostroenie, 1968, p 360, in Russian.

[11] L.M. Utevskii, E.E. Glikman, G.S. Kark. Reverseable temper brittleness of steel and ferroalloy. M.: Metallurgia, 1987, p. 222, in Russian

[12] G.S. Kark, A.A. Astafiev. Temper brittleness of the low-alloy Cr-Ni-Mo steels. V: Metallovedenie i termicheskaja obrabotka stalei dlja oborudovania energoustanovok. Trudi CNIITMASH №177, Moscow, 1983, p 97, in Russian

[13] X. Zhu, J. Joyce, Eng. Fract. Mech., 2012, 85, pp 1-46.

[14] Ja.R. Magnus, P.K. Katishev, A.A. Pereseckii. Econometric. Initial course. Delo, Moscow, 2004, in Russian. 